Bentham open
CrossMark
Content list available at: www.benthamopen.com/TOCIEJ/
DOI: $10.2174 / 1874149501711010768$

RESEARCH ARTICLE

\title{
Doing More with Less: Application to Transmission Structures
}

\author{
Marlon W. Vogt \\ Senior Engineer, Transmission-Distribution-Communications, Ulteig Engineers, Hiawatha, Iowa, USA
}

Received: April 6, 2017

Revised: March 10, 2017

Accepted: June 1, 2017

\section{Abstract:}

\section{Introduction:}

Common theme within the electric utility industry is doing more work with fewer resources. Shrinking staff resources and budgets create challenges in light of the continuing strong investment required for national lifeline infrastructure projects.

\section{Methods:}

The presentation will define and address one traditional type of waste - overproduction, particularly applied to the design of electric utility transmission structures.

\section{Results and Conclusion:}

It will illustrate a variety of typical design choices and the risks in making design decisions that result in larger than necessary, and thus more expensive, structures.

Keywords: Clearances, Foundations, Loads, Overproduction, Transmission, Structures, Waste.

\section{INTRODUCTION}

The electric utility industry in the United States is a critical lifeline industry. It is undergoing disruptive changes that are challenging the traditional way of doing business. The growth of renewable energy generation sources, such as wind and solar, is radically changing the economics and operation of the grid. In addition to this, the fact is that the workforce is aging and the rate of growth of the working-age population is declining. Consequently, there is a gap between the required workforce and the number of working adults. This gap is expected to widen.

If the amount of work to be done does not significantly change, and the workforce does not grow, the end result is a growing need to 'do more with less' and "work smarter, not harder'.

One way to offset this gap is to implement new technologies. This allows an industry to maintain productivity with fewer workers.

Another strategy is to improve the existing process efficiencies. When an organization improves efficiency by eliminating process waste, it can improve operations, more efficiently use its available resources and do so by reducing capital expenditures.

The classic example of 'doing more with less' is the Toyota Lean Production system [1] that revolutionized the auto industry.

"Lean production is 'lean' because it used less of everything compared with mass production-half the human effort in the factory, half the manufacturing space, half the investment in tools, half the engineering hours to develop a

\footnotetext{
* Address correspondence to this author at the Ulteig Engineers, Inc., 109 N. Center Point Road, Hiawatha, Iowa 52233, USA, Tel: 3192863010 , Fax: 888858 3440, E-mail: marlon.vogt@ulteig.com
} 
new product in half the time. Also, it requires keeping far less than half the needed inventory on site, results in fewer defects, and produces a greater and ever growing variety of product."

\section{DEFINITION OF WASTE}

There are seven classical types of waste. For the purposes of this discussion, this paper will focus on only one as it is related to transmission structures-overproduction. By definition, overproduction is simply making more of something than required. In the Toyota automobile production process, making more cars than they can sell is waste. In the case of a transmission structure, waste of overproduction can be illustrated by a structure that is excessively strong, tall or heavy.

This paper provides various design issues that a line designer can consider to reduce waste of overproduction and thus the cost of a transmission system.

\section{OPPORTUNITIES TO REDUCE TRANSMISSION STRUCTURE WASTE}

A transmission line is essentially a structural system that includes conductors, the supporting structures and foundations. For the purpose of this discussion, it is understood that typically a larger structure also results in a larger and more expensive foundation system, whether it be pole embedment or a separate foundation to which it is attached. All references to increased structure costs can be assumed to include corresponding costs of the associated foundation.

\subsection{Conductor Considerations}

Conductor selection is often the first decision which is followed by many other design choices. Much of the structural loading results from the conductor tension, motion and weather loading, including ice, wind and temperature. Conductors impose vertical, horizontal and longitudinal loads onto the structure, which must safely resist these loads. The ground line moment resultant of these loads must also be adequately resisted by the foundation system. Basic statics gives us the understanding that the larger the loads or taller the structure above e ground, the more material is required in the structure; this adds more weight and cost. The increased cost is made up of both structure material and construction costs.

\subsection{Clearances}

The National Electrical Safety Code or NESC [2], mandates minimum clearances between energized conductors and also between conductors and various objects. Tables $\mathbf{1}$ and $\mathbf{2}$ show typical conductor clearances to ground and phase to phase spacing (modified RUS values) [3]. Fig. (1) depicts the physical definition of the clearances. Many utilities mandate these minimum clearances, but then add extra 'buffer' dimensions, $0.61 \mathrm{~m}$ to $1.52 \mathrm{~m}$ ( $2 \mathrm{ft}$. to $5 \mathrm{ft}$.), or more, to provide an additional margin of safety. This 'buffer' is used to account for variances in construction, conductor sagging and weather loads that exceed assumptions. But for every incremental increase in ground clearance and phase spacing, the conductors are moved higher above the ground, resulting in a taller/larger structure and increased ground line moment. Line designers should therefore choose clearance margins carefully, as all increases will raise the costs.

Table 1. Typical conductor vertical clearances * to ground, roads, rails or water surface in meters (feet).

\begin{tabular}{|c|c|c|c|c|c|c|}
\hline \multirow{2}{*}{ Object Crossed } & \multicolumn{5}{|c|}{ Nominal Phase-to-Phase Transmission Voltage (kV) } \\
\cline { 2 - 7 }$(1)$ & $\mathbf{3 4 . 5}$ to $\mathbf{4 6}$ & $\mathbf{6 9}$ & $\mathbf{1 1 5}$ & $\mathbf{1 3 8}$ & $\mathbf{1 6 1}$ & $\mathbf{2 3 0}$ \\
\hline $\begin{array}{c}\text { Maximum Operating Voltage } \\
\text { (Phase-To-Phase) }\end{array}$ & - & 72.5 & 120.8 & 144.9 & 169.1 & 241.5 \\
\hline $\begin{array}{c}\text { Maximum Operating Voltage } \\
\text { (Phase-To-Ground) }\end{array}$ & -- & 41.8 & 69.7 & 83.7 & 97.6 & 139.4 \\
\hline $\begin{array}{c}\text { Roads, streets subject to truck traffic; Alleys, parking lots, driveways; other } \\
\text { lands cultivated traversed by vehicles }\end{array}$ & $5.7(18.7)$ & $5.9(19.2)$ & $6.1(20.1)$ & $6.3(20.6)$ & $6.4(21.0)$ & $6.8(22.4)$ \\
\hline Railroad Tracks & $8.1(26.7)$ & $8.3(27.2)$ & $8.6(28.1)$ & $8.7(28.6)$ & $8.8(29.0)$ & $9.3(30.4)$ \\
\hline Spaces and ways accessible to pedestrians only & $4.5(14.7)$ & $4.6(15.2)$ & $4.9(16.1)$ & $5.1(16.6)$ & $5.2(17.0)$ & $5.6(18.4)$ \\
\hline Water Areas - No Sail Boating & $5.2(17.2)$ & $5.4(17.7)$ & $5.7(18.6)$ & $5.8(19.1)$ & $6.0(19.5)$ & $6.4(20.9)$ \\
\hline Water Areas - Sail Boating Suitable (Less than 20 acres) & $6.3(20.7)$ & $6.5(21.2)$ & $6.7(22.1)$ & $6.9(22.6)$ & $7.0(23.0)$ & $7.4(24.4)$ \\
\hline Water Areas- Sail Boating Suitable (Over 2000 acres) & $12.4(40.7)$ & $12.6(41.2)$ & $12.8(42.1)$ & $13.0(42.6)$ & $13.1(43.0)$ & $13.5(44.4)$ \\
\hline * Does not include any buffer or adder. (Source: RUS) & & & &
\end{tabular}


Table 2. Typical phase separation at structure* in meters $(f e e t)$.

\begin{tabular}{|c|c|c|c|c|c|c|}
\hline \multirow{2}{*}{-} & \multicolumn{5}{|c|}{ Nominal Phase-to-Phase Transmission Voltage, (kV) } \\
\cline { 2 - 7 } & $\mathbf{3 4 . 5}$ to $\mathbf{4 6}$ & $\mathbf{6 9}$ & $\mathbf{1 1 5}$ & $\mathbf{1 3 8}$ & $\mathbf{1 6 1}$ & $\mathbf{2 3 0}$ \\
\hline Spacing between .... & $\mathbf{( 2 )}$ & $\mathbf{( 3 )}$ & $\mathbf{( 4 )}$ & $\mathbf{( 5 )}$ & $\mathbf{( 6 )}$ & $\mathbf{( 7 )}$ \\
\hline Phase Wires of Same Circuit & \multicolumn{3}{|c|}{ Minimum Vertical Separation Required in meters $(\text { feet })^{1,2}$} \\
\hline Phase Wires and Overhead Ground Wires (OHGW) & $0.82(2.7)$ & $1.07(3.5)$ & $1.55(5.1)$ & $1.80(5.9)$ & $2.04(6.7)$ & $2.77(9.1)$ \\
\hline
\end{tabular}

(Source: RUS) * Does not include any buffer or adder. ${ }^{1}$ An additional $0.61 \mathrm{~m}(2 \mathrm{ft}$.) should be added to the above clearances in areas of severe icing. Applicable for Standard RUS Structures only

\subsection{Design Loads}

The NESC mandates wind and ice loads on transmission conductors. Typical wind and ice loading maps are generally accurate and reliable. However, some utilities add additional wind and/or ice loads to the conductors based on local and historical experience. Increasing radial ice will increase vertical loading as well as horizontal loads due to the wind applied to a larger cross-section of iced conductor. Both of these increase the structure cost.

It is common for line designers to include special load cases to the structure design. One such case is construction loading. This can be extra vertical load due to the increased conductor angle and tension during conductor installation. Sometimes extra longitudinal load is required to account for conductor installation forces; for example, this happens when the pulling hardware gets hung up in the conductor pulling sheaves, or rollers. Another special load case is for broken conductor(s). This case is typically used at large angle and dead end locations. This represents possibly the most severe unbalanced tension loading case that impacts the structure.

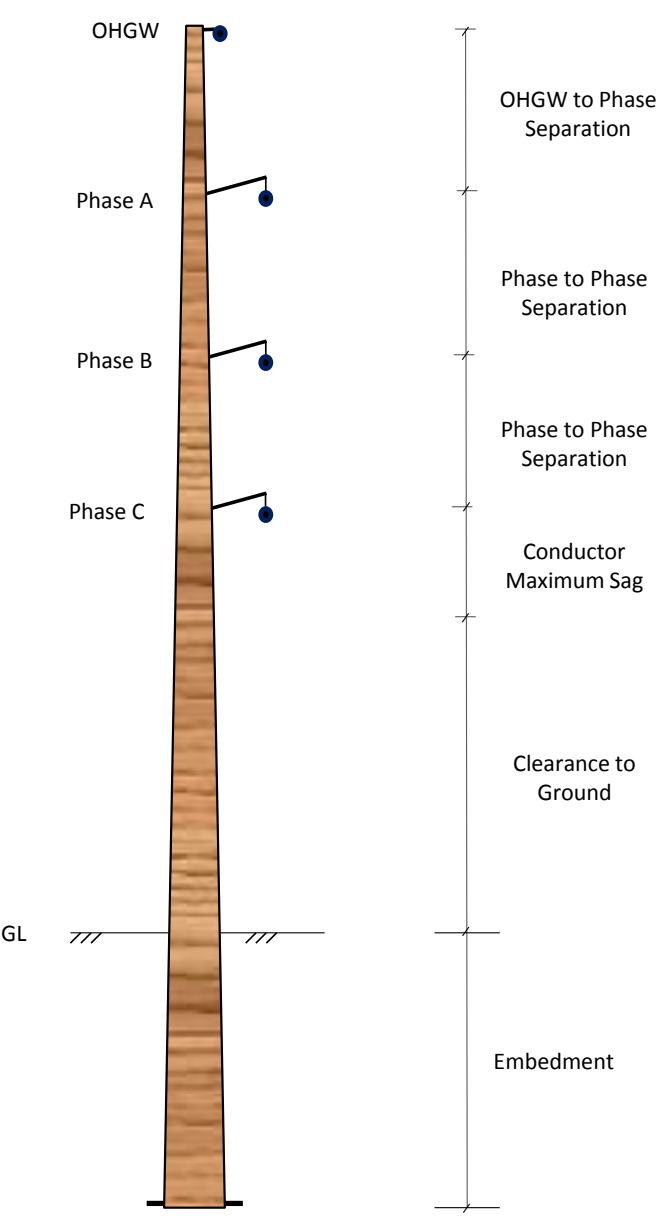

Fig. (1). Tangent Transmission Pole - Components of Height above Ground. 
The high shear and tension loads that can result from construction and broken conductor loads can significantly increase the size of both the conductor support member designs (insulators and/or arms) and the structure itself; both of them increase the costs.

\subsection{Galloping}

In certain parts of the country, transmission conductors experience a phenomenon called galloping. This occurs when a layer of ice is deposited on a round conductor. The ice can change the shape of the conductor and essentially turn it into an airfoil. When the ice and wind conditions are just right, the conductor starts to 'fly' and this movement is called galloping.

Galloping typically resolves itself into one of two modes, single- or double-loop in Fig. (2). In a single-loop mode, the conductor moves in much the same way as a jump rope between the structures. The maximum amplitude occurs at the half-span point. In the double-loop mode, the conductor has a node mid-way between the structures and it appears like two jump ropes. Here the maximum amplitude occurs at quarter-span points. The type of conductor galloping, and thus its amplitude, are largely determined by the span length between the structures as well as the conductor tension. Double-loop galloping is typically seen in spans greater than 213 meters (700 feet). Single-loop galloping typically happens in span lengths below this threshold. It is important to note that galloping does not always restrict itself to these rules of thumb.

Design choices related to galloping are important. For both galloping modes, the line designer must ensure that the conductors do not coincide as a result of the movement. The primary way to ensure conductors' separation is to increase the spacing of structural conductor attachment members. Increased conductor spacing results in taller, heavier, and more expensive structures. Adjusting conductor design tensions is also an alternative way of controlling galloping.

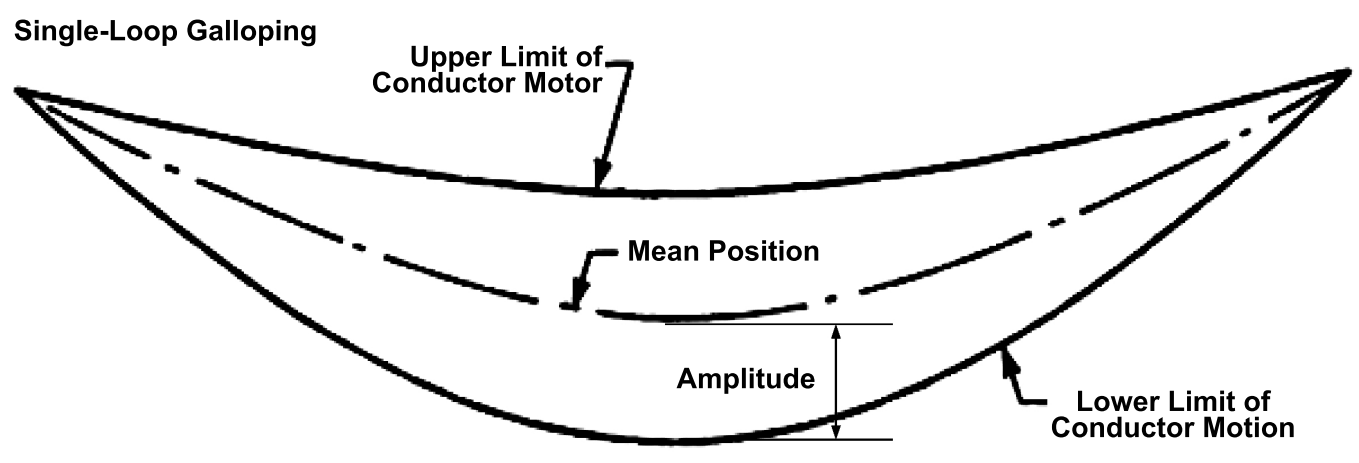

\section{Two-Loop Galloping}

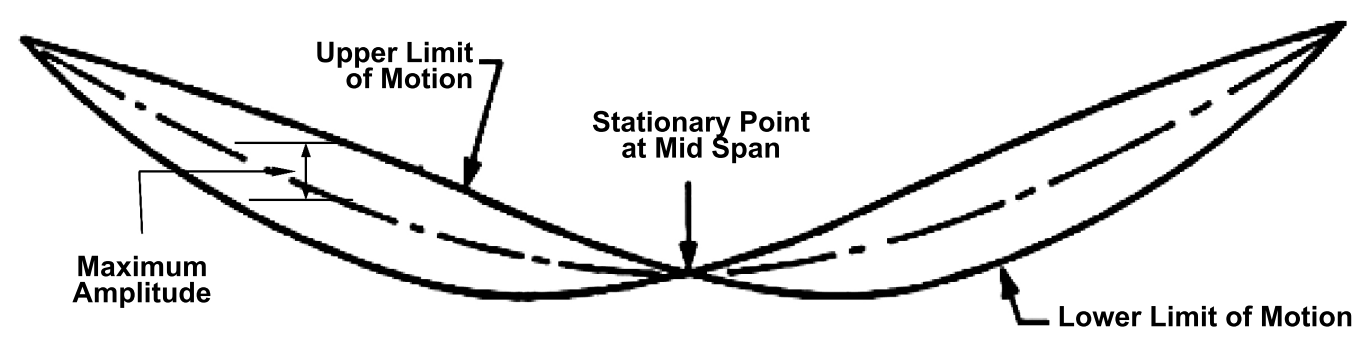

Fig. (2). Single and double loop conductor galloping.

\subsection{Aeolian Vibration}

Another wind-related phenomenon is Aeolian vibration. This is typically a high frequency, low amplitude movement generated by a low-velocity, steady wind blowing across the wires. It is caused by vortex shedding. When wind flows around a conductor or structural member, vortices are formed on the downwind side of the object, and they detach periodically from alternating sides of the body. Under suitable conditions, this causes the conductor or structural member to vibrate and oscillate - ultimately causing fatigue damage.

There are various options to manage component vibration and eliminate damage. Common techniques include 
reducing tensions, using armor rods and cushioned suspensions, increasing the member size or installing damping devices to the members. Some utilities adopt self-damping and special purpose conductors to reduce vibrations. All of these can increase the structure cost.

Many design decisions related to conductors can impact the total cost of the structural system. It is critical to carefully consider these choices in order to avoid over-designing the system, which can result in overproduction costs.

\section{STRUCTURAL CONSIDERATIONS}

Current transmission design tools provide detailed modeling and structural capacity reporting features. Regardless of the structure material or configuration, a line designer can predict how much of the structural capacity will be used for each application. The capacity of all structural members such as cross arms, insulators, guy wires and other components can also be known. A key design element for the line designer to determine is how much total structural capacity is used and how much marginal capacity should be held in reserve. This decision can have an impact on the total line cost. Intuitively, a line composed of structures using $50 \%$ of strength capacity will be costlier than a line using $90 \%$ capacity.

\subsection{Line Angles}

Transmission lines typically contain a majority of tangent (no line angle) structures. However, it is common for the installed locations of tangent structures to vary from design and thus have a small line angle. This can be caused by construction considerations, subsoil issues, right-of-way limitations etc. Consequently, it is common to design some small angle loading into most tangent structures to provide a bit of excess capacity to allow for these circumstances.

Equations (1a) to (1c) show the expressions for calculating vertical, transverse and longitudinal loads on a transmission structure subject to a line angle ' $\theta$ '. Fig. (3) shows the associated wire and load configurations.

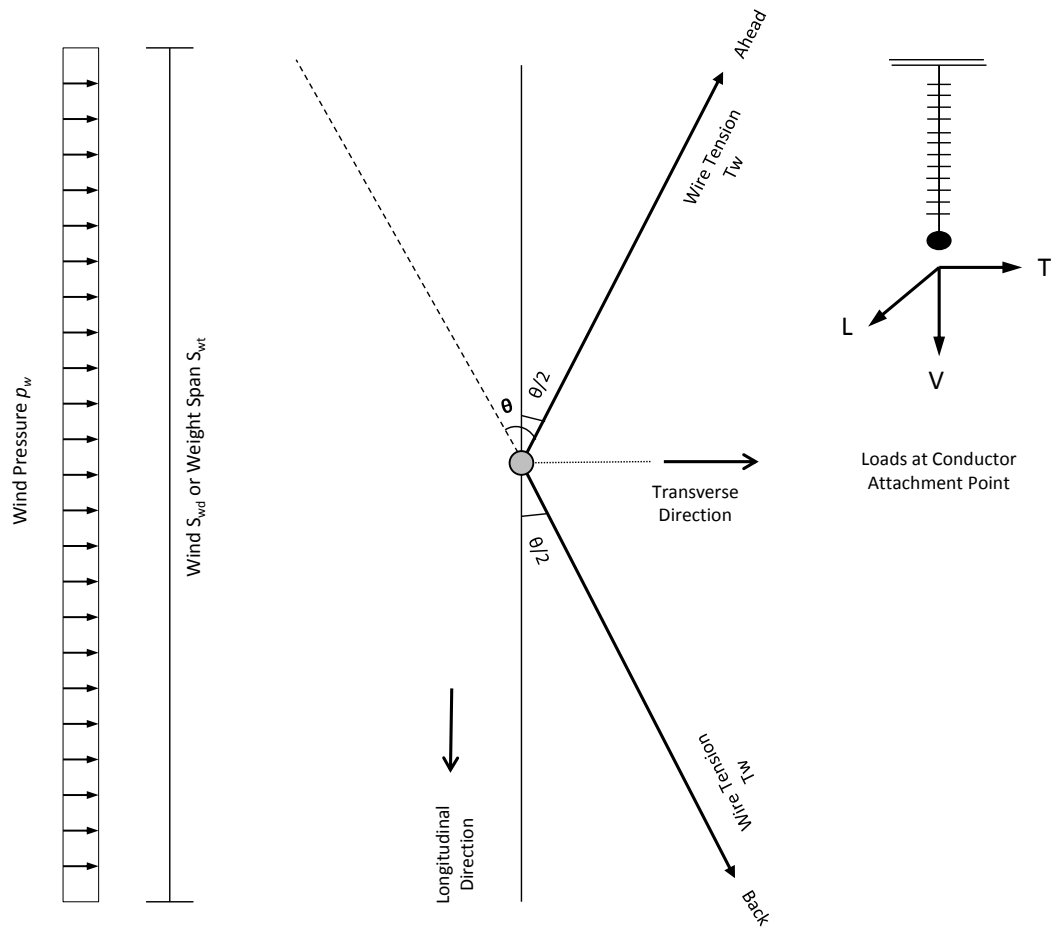

Fig. (3). Effect of line angle on wire loads.

$$
\begin{aligned}
& \text { Vertical V }(\mathrm{kN})=\left\{\left[\left(2 * t_{r i}+d_{w}\right)^{2}-d_{w}^{2}\right] * \frac{1}{4} \pi * \gamma_{i c e}+w_{b w}\right\} * L F_{v} * S_{w t} \\
& \text { Transverse } \mathrm{T}(\mathrm{kN})=\left(2 * t_{r i}+d_{w}\right) * S_{w d} *\left(p_{w}\right) * L F_{t}+2 \sin \left(\frac{\theta}{2}\right) * T_{w} * L F_{w t} \\
& \text { Longitudinal } \mathrm{L}(\mathrm{kN})=\cos \left(\frac{\theta}{2}\right) * T_{w} * L F_{w t}+\cos \left(\frac{\theta}{2}\right) *\left(-T_{w}\right) * L F_{w t}=0
\end{aligned}
$$




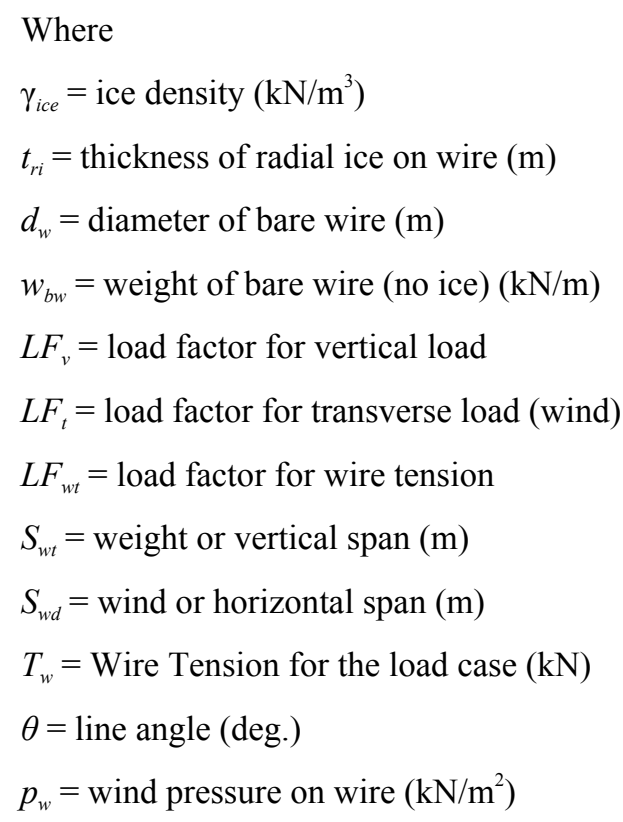

From Equation ( $1 \mathrm{~b})$, one can observe that the transverse load component due to line angle (shaded portion) for $\theta=$ $2^{\circ}$ is approximately 4 times that of $\theta=0.5^{\circ}$. This can impact the cost of the total cost of the line if an unreasonable line angle is used on tangent structures.

\subsection{Deflection Limits}

Line designers often limit the overall pole deflection for a number of valid reasons, including maintaining clearances and aesthetics. One typical pole top deflection limit is $2 \%$ of pole height above the ground for normal operating conditions (no wind, no ice, $60^{\circ} \mathrm{F}$ weather). Generally, the smaller the deflection limit, the stiffer the structure must be. A stiffer structure usually requires thicker steel in order to achieve the specified limits. Unrealistically restricted deflection can significantly increase the cost of a structure. Fig. (4) illustrates the effects of pole top deflection limits on the lateral stiffness required, which in turn affects the section properties such as the moment of inertia, I.

For example, we quantitatively considered two double-circuit $24.4 \mathrm{~m}$ (80 ft.) tubular steel structures with identical spans and conductor configurations. One structure's top deflection was limited to $15.2 \mathrm{~cm}$ (6 in.), while allowing the other structure to have no deflection limit. The difference in weight between these two poles would be approximately 386 kilograms $(850 \mathrm{lbs}$.). If the steel costs $\$ 4.50 / \mathrm{kg}$, the extra cost for satisfying the deflection limit is approximately $\$ 1,740$ per pole. Multiply that by the number of tangent structures in a line and it can become an important cost factor. Therefore, deflection limit decisions must be made carefully.

\subsection{Base Diameter}

At times, a line designer will limit the base diameter of the structure. This can often happen because of construction, foundation or right-of-way restrictions, among others. Similar to deflection limits, restricting the base diameter simply requires additional material in the structure (extra thickness) to resist the loads. This drives up the cost.

\subsection{Guying}

Most transmission lines do not connect the substation terminals in a straight line. They require angles and dead ends in the system. Two primary structure choices are available for these situations - guyed and self-supporting. In a guyed scenario, the structure simply serves as a strut and primarily resists vertical loads. As long as it does not buckle, it can safely resist considerable axial loads. The guy wires resist the horizontal loads. Generally speaking, the more guy wires that can be used on an angle or dead-end application, the cheaper the structure. A self-supporting structure, however, must resist large overturning moments, without lateral (guyed) support, thus increasing the size of the structure as well as the foundation system.

\subsection{Future Enhancements}

Another common practice is to operate a transmission system at one voltage, but design it for a potential future, 
higher voltage. These structures are insulated and have spacing appropriate to the higher voltage. In some situations, structures are designed to facilitate adding another circuit in the future. Both of these increase the pole height and/or moments, as well as the cost. Particular care should be taken to carefully evaluate this option to make sure that the extra structure cost matches the probability of a future voltage uprate.

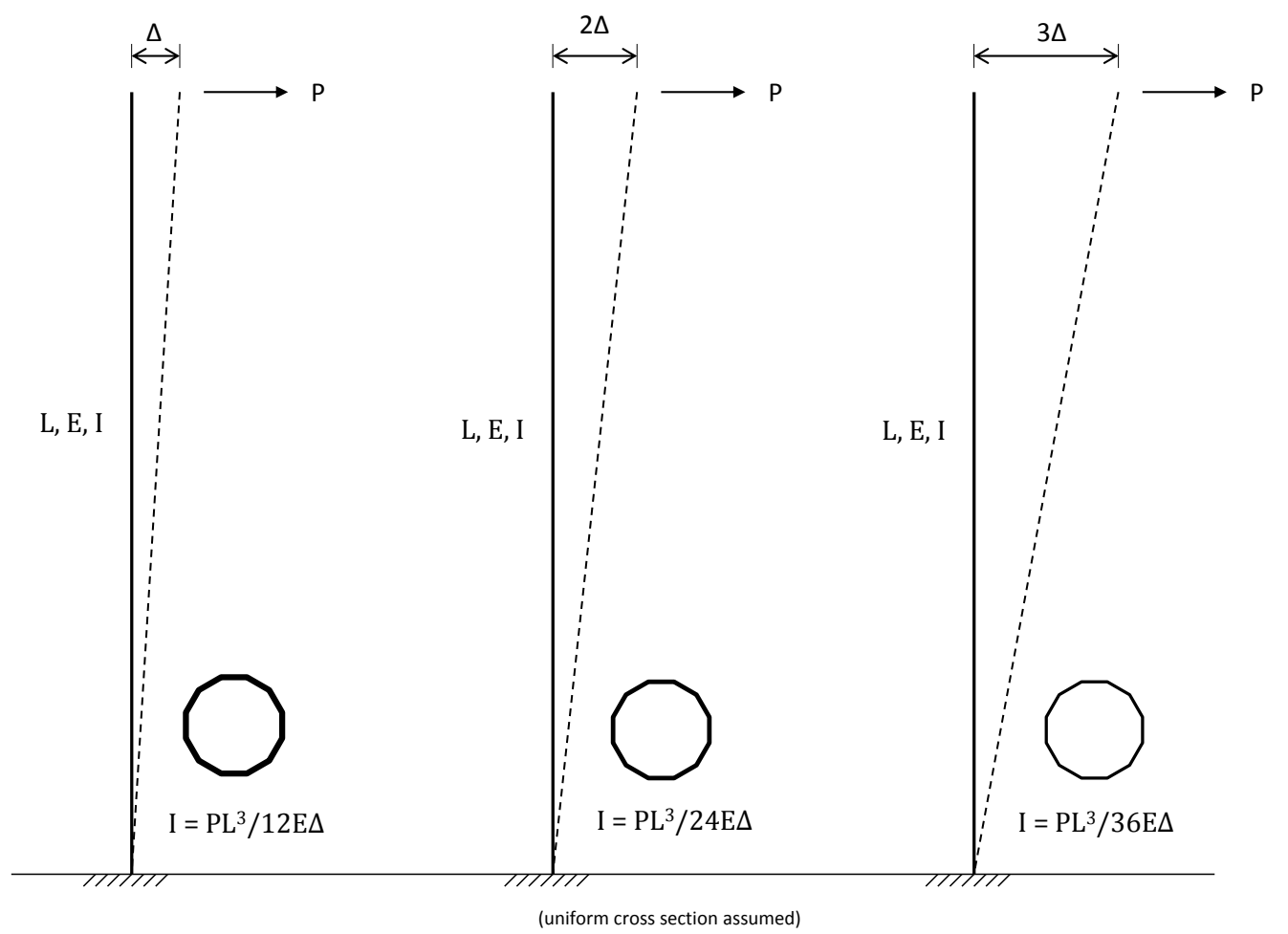

Fig. (4). Effect of deflection constraints on pole size.

\subsection{Protective Coatings}

Coating systems are an important consideration for transmission structures. Common solutions include galvanizing, painting and weathering steel. All of these have strengths and weaknesses and all have long-term maintenance realities. Selecting galvanized structures over weathering steel will generally increase the initial cost. Using weathering steel in an incorrect application may result in long-term performance issues and future costs (pack out on lattice joints, color bleeding onto surfaces, etc.). Painted structures will have long-term maintenance requirements that affect the cost.

\subsection{Specifications}

The transmission line owner should also be aware that certain requirements of the structure designer/fabricator can increase the structure cost due to manufacturing complexity. Design specification requirements often result in significant fabrication efforts, thus increasing the cost of the structure. Examples of these requirements might include adding internal pole pipes between tubular steel bolt holes, hand welding a large number of climbing ladder clips to the exterior of a structure, construction and maintenance holes, vangs and appurtenances and requiring backing plates on the inside of structures for certain welds. Line designers should carefully consider the need and application for these items and account for the impact on structure cost.

\section{FOUNDATION CONSIDERATIONS}

A transmission line is an integrated system involving the conductors, structures and their foundations. These foundation systems provide additional opportunities to save costs, to be more efficient and 'do more with less'.

\subsection{Geotechnical Report}

The basis of foundations are the geotechnical investigations that were utilized in the eventual design. Since soil is a highly variable and unpredictable material, there is always the risk of making educated assumptions often based on 
limited data. This can lead to overly conservative design, and thus increased foundation costs. A number of foundation design software packages [4 - 6] are currently available; however, the type and nature of soil data required for these programs are different. Therefore, soil reports must be customized to satisfy the requirements of the software to be used. Since foundation designs rely on particular soil properties, we must ensure what properties are needed and clearly communicated then to the geotechnical engineer. Testing for unnecessary properties, costs, time and money.

It is often a challenge to determine the number of soil borings to perform along a line route. One approach, if practical, is to do a soil boring at every structure location. Another approach is to take borings at all angles and dead ends, and then get at least one boring per kilometer in tangent or straight line sections. For the case of a line using drilled pier foundations, more borings have the benefit of reducing the foundation design conservatism as it requires fewer assumptions. In many cases, this reduces the diameter and/or depth of a drilled pier foundation and more than offsets the cost of the geotechnical sampling and testing for that particular pole location.

\subsection{Design Methods}

Numerous design approaches are available for foundations. It is important to match the design approach to the type of foundation being considered. For example, a design method that was developed for piles may not be the best fit if applied to drilled pier foundations. Similarly, direct embedment designs involve a somewhat different set of parameters compared to drilled piers or isolated footings. Therefore, we must match the design approach to the type of foundation in order to minimize overly conservative, and thus costly, foundations.

\subsection{Load and Strength Factors}

All the transmission structures and line design are now LRFD-based. Line designers and foundation engineers should therefore closely coordinate their respective load and resistance factors. It is not unusual for these factors to double-up and thus increase the costs due to overly conservative design.

\subsection{Pier Deflections}

Another important decision for a drilled pier concrete foundation is the selection of pier deflection and rotation limits. What amount of deflection at the top of a foundation can be allowed and what are its implications for the structure and conductors? Will a small amount of lateral movement at the ground line significantly compromise clearances? Depending on the height of the pole, a small amount of rotation at ground level can create a much larger movement at the top of the pole, potentially compromising phase clearances. Deflection and rotation limits are important factors to be considered when writing the foundation specifications. These choices can have a significant impact on performance and cost. Current industry standards allow $7.5 \mathrm{~cm}$ to $12.5 \mathrm{~cm}$ (3 in.to 5 in.) total deflection and $1^{\circ}$ to $1 \frac{1}{2}{ }^{\circ}$ total rotation at ground level.

\subsection{Pier Diameter}

Drilled shaft diameters are sized as a function of applied lateral loads and soil profile. Line designers often face the situation where limiting the pier deflection requires either increasing the diameter of the pier or install it deeper into the soil. Depending on the design situation at the specific location, it is recommended that the latter option can be adopted: longer shaft length ' $L$ ' instead of larger diameter ' $D$ '.

$$
\mathrm{V}=\pi D^{2} L / 4
$$

As Equation (2) shows, the volume of concrete ' $\mathrm{V}$ ' varies according to the square of the diameter. As opposed to the deflection limits for pole tops, restricting the pier diameter simply reduces the overall concrete volume of the pier. This helps reduce the concrete costs.

\subsection{Below-Ground Coatings}

Many steel poles are direct embedded in the native soil and do not use a separate foundation system. The embedded sections of these poles are often coated with a corrosion-inhibiting material. Another technique is to add a separate, sacrificial layer of steel for some distance above and below the anticipated ground line of the pole. This tends to be the most active corrosion zone, thus the concern. Decisions related to the type and extent of both the coating and ground sleeves can add up to significant costs for the transmission line. These choices deserve reasoned evaluation in order to 
control costs.

\subsection{Staff Considerations}

Design labor costs are also worth mentioning. Overproduction waste can occur when a more experienced, higherpaid staff performs tasks that a less-experienced and typically less-expensive staff could adequately do. This is often called 'right-skilling': matching the correct skill sets to the appropriate design functions. Although the engineering labor cost is typically a small percentage (between $2 \%$ to $4 \%$ ) of the total project cost, it does play a significant role in controlling the costs and being able to 'do more with less'.

\section{CONCLUSION}

Transmission structures are used in a wide variety of applications. They are used in widely-different weather conditions, topography, voltages etc. Structures can depend on numerous materials: wood, laminated wood, steel, concrete, lattice tower and fiber reinforced polymer (fiberglass). Line designers can also select from many different structural configurations: single pole, multi-pole, lattice etc.

This paper is not intended to cover all possible voltage levels, structural types and applications. However, the overarching general principles are presented apply to a broad range of situations. This will hopefully provide a useful list of considerations to reduce the cost for line designers.

Line, structure and foundation designers understand the basic principles of waste and allow that understanding to guide their design choices, thus realizing an economical and efficient end product. They effectively can "do more with less'.

\section{NOTATION}

\begin{tabular}{|c|c|c|}
\hline$d_{w}$ & $=$ & Diameter of bare wire \\
\hline D & $=$ & Pier diameter \\
\hline $\mathbf{E}$ & $=$ & Modulus of elasticity \\
\hline I & $=$ & Moment of inertia \\
\hline $\mathbf{L}$ & $=$ & Pier length \\
\hline$L F_{v}$ & $=$ & Load factor for vertical load \\
\hline$L F_{t}$ & $=$ & Load factor for transverse load (wind) \\
\hline $\boldsymbol{L} \boldsymbol{F}_{w t}$ & $=$ & Load factor for wire tension \\
\hline $\mathbf{P}$ & $=$ & Lateral load on cantilever \\
\hline$S_{w t}$ & $=$ & Weight or vertical span \\
\hline$S_{w d}$ & $=$ & Wind or horizontal span \\
\hline $\boldsymbol{T}_{w}$ & $=$ & Wire Tension for the load case \\
\hline $\mathbf{V}$ & $=$ & volume \\
\hline $\boldsymbol{p}_{w}$ & $=$ & Wind pressure on wire \\
\hline$t_{r i}$ & $=$ & Thickness of radial ice on wire \\
\hline $\boldsymbol{w}_{b w}$ & $=$ & Weight of bare wire (no ice) \\
\hline$\theta$ & $=$ & Line angle (deg.) \\
\hline$\Delta$ & $=$ & Cantilever tip deflection \\
\hline$\gamma$ & $=$ & Ice density \\
\hline
\end{tabular}

\section{CONSENT FOR PUBLICATION}

Not applicable.

\section{CONFLICT OF INTEREST}

The author declare no conflict of interest, financial or otherwise. 


\section{ACKNOWLEDGEMENTS}

Declared none.

\section{REFERENCES}

[1] J.P. Womack, D.T. Jones, and D. Roos, The Machine that Changed the World, Rawson Macmillan: New York, 1990.

[2] National Electrical Safety Code, ANSI-C2, Institute of Electrical and Electronics Engineers, 2012.

[3] Bulletin 1724E-200, “Design Manual for High Voltage Transmission Lines”, Rural Utilities Service, United States Department of Agriculture: Washington, DC, 2015.

[4] "CAISSON TM, Analysis and Design of Reinforced Concrete Pier Foundations, Power Line Systems (PLS)", Madison, Wisconsin, USA, 2012

[5] MFAD ${ }^{T M}$, Moment Foundation Analysis and Design Version 5.1, Electric Power Research Institute (EPRI), Palo Alto, California, USA, 2014.

[6] LPILE ${ }^{T M}$, Program for the Analysis of Piles and Drilled Shafts under Lateral Loads, Users' Manual, Ensoft Inc., Austin, Texas, USA, 2013.

(C) 2017 Marlon W. Vogt.

This is an open access article distributed under the terms of the Creative Commons Attribution 4.0 International Public License (CC-BY 4.0), a copy of which is available at: https://creativecommons.org/licenses/by/4.0/legalcode. This license permits unrestricted use, distribution, and reproduction in any medium, provided the original author and source are credited. 